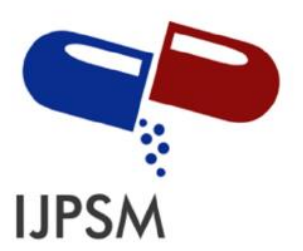

Georgiana Farrugia Bonnici, Int. Journal of Pharmaceutical Sciences and Medicine (IJPSM),

Vol.6 Issue. 4, April- 2021, pg. 92-115

ISSN: 2519-9889

Impact Factor: 3.426

\title{
Are General Practitioners' Imaging Requests Indicated for Diagnostic or Clinical Management Purposes? A Review of the Literature
}

\author{
Georgiana Farrugia Bonnici \\ Department of Family Medicine, Faculty of Medicine \& Surgery, University of Malta, gfar0010@um.edu.mt \\ DOI: 10.47760/ijpsm.2021.v06i04.008
}

\begin{abstract}
Requests for useful imaging investigations are primarily those whose results, if positive or negative, will add confidence to the referrers' diagnoses or aid in any future clinical management plans. Hence, referrers need to be aware if they are about to repeat investigations that have already been recently done; if they intend to undertake investigations when their results are unlikely to affect the patients' diagnoses or clinical management; if they are seeking to investigate too early, if they are about to choose the wrong imaging modality, or if they are failing to provide all the appropriate clinical information that seeks to address the clinical questions that need to be answered. This literature review has highlighted several important aspects that are already known with respect to the radiation dose justification and optimisation. Moreover, it has evaluated the current main issues relating to the physicians' awareness in radiation safety and imaging referral processes, as well as the appropriateness behind requesting ionizing imaging investigations. Certain gaps and conflicts in the literature were also identified.
\end{abstract}

Keywords: family medicine, general practitioners, imaging, justification, indication.

\section{1 - Introduction to the literature review}

Throughout the past decade, the extent of ionizing radiation exposures amongst patients from repeated plain x-ray imaging investigations has increased dramatically (Fazel, et al; 2009; Lauer, 2009; European Society of Radiology, 2011; Vilar-Palop, et al., 2018). Non-radiologists are more likely to request plain x-ray examinations. Moreover, consultations with a radiologist prior to submitting these plain $\mathrm{x}$-ray imaging requests are usually not required. Primary care doctors have a pivotal role in acting as daily gatekeepers to specialist care (Morgan, et al., 2019). Thus, the professional responsibility of requesting appropriate imaging investigations starts with the referrers. This vital task is essential for patients to benefit from the reduction of ionizing radiation risks and the uniformity of care, to reduce the number of unhelpful imaging examinations, to support rapid diagnoses which may ultimately shorten the clinical management pathways, as well as to ensure that all health care resources are being used efficiently by avoiding unsustainable costs and excessive departmental work-loads (Royal College of Radiologists (RCR), 2017).

The justification of an imaging request involves the weighing of all potential benefits against the potential detrimental risks for the individuals undergoing the procedures. In fact, the International Commission on Radiation safety (IRCP) Publication 73, defines the justification of medical radiation exposure as follows:

"No practice involving exposures to radiation should be adopted unless it produces at least sufficient benefit to the exposed individuals or to society to offset the radiation detriment it causes" (Sang-Geon, et al., 2017). 


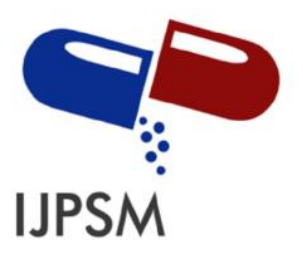

Georgiana Farrugia Bonnici, Int. Journal of Pharmaceutical Sciences and Medicine (IJPSM),

Vol.6 Issue. 4, April- 2021, pg. 92-115

ISSN: 2519-9889

Impact Factor: 3.426

There are ongoing debates as to who is responsible to carry out this important task; albeit a sound justification process should ideally involve the referring physicians, the radiographers as well as the radiologists (Mendelson and Montgomery, 2016). Ideally, the professional relationships between radiologists and general practitioners should involve brief consultations, rather than just resorting to the traditional requesting and reporting scenarios (Mendelson and Montgomery, 2016). As defined in the European Directive 2013/59/EURATOM:

"A high level of competence and a clear definition of responsibilities and tasks among all professionals involved in medical exposures are fundamental to ensure the adequate protection of patients undergoing medical radio-diagnostic and radio-therapeutic procedures" (European Society of Radiology, 2015).

Moreover, it is vital that those doctors who are involved in requesting various radiological examinations receive sufficient education and training, in order to be able to attain adequate competence in radiation safety (European Society of Radiology, 2015). To be able to justify ionizing imaging procedures, the referring doctors need to be well-aware of the magnitude of the radiation doses to be given to their patients, as well as all possible detrimental effects of these exposures. To some degree, the lack of such awareness, could also be compensated by consulting imaging referral guidelines whenever the need arises (Borgen, et al., 2010).

Requests for useful imaging investigations are primarily those whose results, if positive or negative, will add confidence to the referrers' diagnoses or aid in any future clinical management plans. Hence, referrers need to be aware if they are about to repeat investigations that have already been recently done; if they intend to undertake investigations when their results are unlikely to affect the patients' diagnoses or clinical management; if they are seeking to investigate too early, if they are about to choose the wrong imaging modality, or if they are failing to provide all the appropriate clinical information that seeks to address the clinical questions that need to be answered (European Commission, 2001; RCR, 2017). The efficient and safe use of radiology services should always be encouraged; thus, it is wise for all referrers to consider these aspects prior to referring their patients for any diagnostic imaging investigations.

\section{1 - The literature search and the adopted methodology}

An extensive literature search for this research study was conducted at the Faculty of Health Sciences: Medical School Library at the University of Malta. Most literature sources were obtained online from reputable electronic portals and online University databases, such as $\mathrm{HyDi}{ }^{\circledR}$, PubMed® and Science Direct ${ }^{\circledR}$. The literature search has mainly involved the following keywords, using a Boolean logic: 'justification', 'radiology', 'imaging', 'indication', 'clinical', 'musculoskeletal', 'radiography', 'awareness', 'knowledge', 'radiation safety', 'radiation protection', 'general practice', 'general practitioners' and 'family medicine'. All free-full text research papers that were available in English, which were published between the years 2008 to 2020 were obtained in these specific literature searches. The bibliographies of such publications were also searched for any other potential referencing sources. Whenever possible, primary sources of literature were acquired. The quality, the quantity and the consistency of the various levels of evidence sources were also taken into account. In the analysis of any interventional-based studies, the PICO (Problem/Population; Intervention; Comparison; Outcome) format was applied in order to be able to generate evidence-based perspectives (LoBiondo-Wood and Haber, 2017). 


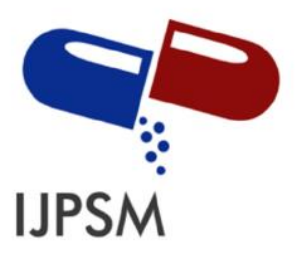

Georgiana Farrugia Bonnici, Int. Journal of Pharmaceutical Sciences and Medicine (IJPSM),

Vol.6 Issue. 4, April- 2021, pg. 92-115

ISSN: 2519-9889

Impact Factor: 3.426

In total, this systematic review includes an assessment of the collective findings from 55 primary sources of literature; including the critical appraisal of several research studies, systematic reviews, clinical practice guidelines as well as other relevant primary sources of literature. Considering that the author wanted to gain as many explorative insights as possible on this particular research topic, the literature search was not restricted by any types of research study designs, methodology, levels of evidence or outcomes. Albeit, all the strictly opinion-based articles with no original research were excluded from this systematic review.

Given the author's geographical background, recent research papers of European origin that were either partly or fully-based in primary care were discussed in greater detail. In addition, those research studies which are solely based in under-developed countries were excluded from this review. Only those findings relating to medical doctors working in either primary care clinics, hospitals as well as outpatients-based settings were included in this systematic literature review. Similar studies which have involved the investigation of the research questions in other allied health-care professions; such as nurses, physiotherapists or radiographers were excluded as they were outside the scope of this literature review.

\section{2 - Diagnostic Reference Levels: The ‘As Low As Reasonably Achievable’ (ALARA) Principle}

Concerns about radiation safety are almost as old as the x-rays spectrum that has been discovered by Wilhelm Röentgen in 1895; because notably, the damaging adverse effects of x-rays on health were also discovered shortly afterwards. This means that no dose of ionizing radiation is considered risk free (Hill and Einstein, 2016). Secondly, repetitive doses of ionizing radiation have a tendency to increase the accumulating risks of potential side-effects. In fact, there are several epidemiologically-based studies which support the claim that despite the risks to any given patient from a plain radiographic imaging study are low, the cumulative burden of disease may still be substantial at the population level (Hill and Einstein, 2016). Nonetheless, radiology has now become a globally-accepted aspect of clinical practice, as often the patients' advantages of undergoing an imaging investigation, outweigh the perceived risks of the radiation exposure (Shannoun, et al., 2008).

In order to restrict the overall radiation exposures of the general population, the use of ionizing radiation is regulated by several recommendations; such as those that have been developed by the International Commission on Radiological Protection, as well as directives, such as the EURATOM European Directive along with other global ordinances and local laws (Shannoun, et al., 2008). The 'As Low As Reasonably Achievable' ALARA principle demands that "during work with ionizing materials, every reasonable effort should be made to minimize the radiation exposure of patients" (Shannoun, et al., 2008). In spite of the professional responsibility for the referrers to abide to the ALARA principle via maximising their patients' radiation safety, it has been reported that the radiation exposures of patients during a significant number of imaging investigations tend to vary by a profound magnitude (Shannoun, et al., 2008). For this reason, diagnostic reference levels (DRLs) have been specified by the Federal Office for Radiation Safety (Shannoun, et al., 2008). DRLs are intended to facilitate the recognition of several clinical situations in which the associated radiation doses are on average unusually high for the patients. If these DRLs are permanently exceeded, significant measures must be taken in attempt to reduce the effective radiation doses (Rehani, 2017). The average ionizing radiation doses from radiography will typically vary according to the patient size, the type of body area being investigated, as well as the radiographic examination techniques and views being chosen (Park and Seung Jung, 2016). It is evident that in plain radiography, the thicker a body part is, the higher the amount of radiation being received by the patient. On average, plain $\mathrm{x}$-rays have a total 


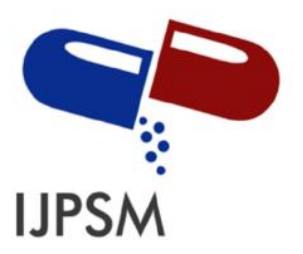

Georgiana Farrugia Bonnici, Int. Journal of Pharmaceutical Sciences and Medicine (IJPSM),

Vol.6 Issue. 4, April- 2021, pg. 92-115

ISSN: 2519-9889

Impact Factor: 3.426

effective dose of $0.01 \mathrm{mSv}$ to $1.5 \mathrm{mSv}$ (Park and Seung Jung, 2016). Contrastingly, in CT, such dose will typically vary between $2 \mathrm{mSv}$ to $20 \mathrm{mSv}$, depending on the examination areas and the imaging protocols being selected by the radiographers (Park and Seung Jung, 2016). This means that CT investigations will incur greater radiation exposure for the patients compared to plain radiography (Shannoun, et al., 2008). This also reflects the greater importance that is associated with the vetting of any highly-specialized imaging procedures, such as CT, RNI or Positron Emission Tomography (PET) with radiologists.

\section{3 - The detrimental stochastic and deterministic effects of ionizing radiation}

The process of ionization in human beings transiently changes molecules, as it bears charged particles that contain enough energy to displace electrons and break chemical bonds (Hill and Einstein, 2016). Once such cellular damage occurs, the cell may not survive, reproduce or perform its vital functions (Vom and Williams, 2017). Alternatively, it may result in a viable but modified cell, which may go on to become cancerous if it is a somatic cell or lead to inherited disease, such as autosomal dominant or autosomal recessive traits, multifactorial inheritance as well as developmental abnormalities, if it is a germ cell (Vom and Williams, 2017).

In addition, it is also known that excessively high radiation doses may cause substantial cell death due to cellular toxicity, which is then expressed as organ or tissue damage (Vom and Williams, 2017). The risks of cancer induction is estimated to increase proportionally to the organ dose, reaching around $0.5 \%$ at an effective dose of 100 mSv (European Society of Radiology, 2011; Vom and Williams, 2017; Khamtuikruia and Suksompong, 2020). Such detrimental risks are known to be higher in females due to their increased susceptibility for breast cancer, as well as the younger the age at the time of exposure due to the increased sensitivity of rapidly dividing cells (European Society of Radiology, 2011; Hill and Einstein, 2016). The breasts, the lungs, the stomach, the colon, the bone marrow and the gonads are known to be more radiosensitive because tumour induction is more likely in these organs than in less radio-sensitive organs such as the brain, the skin, the bones or the salivary glands (Hill and Einstein, 2016). Moreover, several detrimental deterministic effects such as hair loss, eye cataracts, sterility, skin erythema, hypothyroidism, radiation pneumonitis or bone marrow suppression are also known to occur at variable levels of exposure to ionizing radiation (Khamtuikruia and Suksompong, 2020).

The biological impacts of diagnostic imaging exposures is dominated by both the deterministic and the stochastic effects; but the latter is based on the linear-no-threshold hypothesis (Vom and Williams, 2017). The United States (U.S.) National Council on Radiation safety (NCRP) estimates the yearly radiation exposure of an individual to average around $6.2 \mathrm{mSv}$; approximately half of which is coming from imaging procedures and the other half from alternative natural sources, such as radon (Hill and Einstein, 2016). It has also been delineated that in Europe, the overall contribution of ionizing medical imaging procedures to the population radiation exposure is significantly lower than in the U.S. (European Commission, 2008; Zontar, et al., 2015).

\section{4 - The financial burdens and the health risks associated with inappropriate imaging referrals}

Imaging referrals may be inappropriate in several ways such as when the imaging requests are not indicated for the diagnostic or clinical management purposes, when the imaging requests are partly indicated 


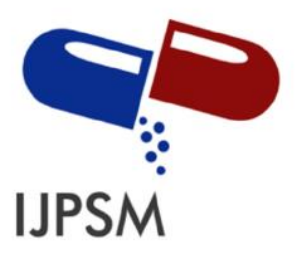

Georgiana Farrugia Bonnici, Int. Journal of Pharmaceutical Sciences and Medicine (IJPSM), Vol.6 Issue. 4, April- 2021, pg. 92-115

ISSN: 2519-9889

Impact Factor: 3.426

because the incorrect modalities are being chosen, or even when the timings of the selected imaging procedures are not ideal (Britt, et al., 2012).

These erratic clinical decisions may result in the use of excess funds from a finite health budget (Britt, et al., 2012; Mendelson and Montgomery, 2016). Secondly, such non-clinically indicated imaging procedures may also involve the use of ionising radiation or exposures to contrast media, which could in turn result in concerns about any future detrimental health risks to the patients. While such risks may be considered as low on an individual basis, they may still eventually accumulate upon repeated investigations (Hill and Einstein, 2016; Mendelson and Montgomery, 2016). Thirdly, false positive and false negative results may emerge from any imaging investigation, either leading to false alarm or inappropriate reassurance. In turn, a cascade of anxiety, investigations and treatment plans may follow, which could also potentially shift the cost-benefit and the risk-benefit ratios of the radiology services to questionable levels (Moynihan, et al., 2012; Mendelson and Montgomery, 2016).

\subsection{1 - What could be the main reasons behind inappropriate imaging referrals?}

There may be ample reasons as to why certain actions in clinical practice may differ from those which are applied in theoretical guidelines. This variance is not always inappropriate, in the sense that sometimes existing documented clinical evidence in imaging referral guidelines might be such a poor-fit for some individual patients (Mendelson and Montgomery, 2016). Nevertheless, non-indicated imaging referrals can occur for multiple reasons; including the lack of awareness about the appropriate investigations of choice or of the potential side-effects of ionizing radiation. This particular reason has in fact been demonstrated in doctors across various clinical specialties, with variable levels of work experience (Mendelson and Montgomery, 2016). Moreover, with on-going technological advances, the perceived importance of the fundamental skills of history-taking and clinical examination amongst medical doctors may also be declining (Mendelson and Montgomery, 2016; Azman, et al., 2019). Time constraints and overconfidence in the accuracy of imaging procedures may also play a pivotal role in the cascade of overinvestigation (Mendelson and Montgomery, 2016).

Another cause of inappropriate imaging referrals may be the low threshold of uncertainty by both medical doctors as well as difficult patients. This is especially relatable to the clinical settings of family medicine, particularly in those cases of somatisation or medically unexplained illnesses (Mendelson and Montgomery, 2016). In such situations, G.Ps are often blinded by the fears of facing any medico-legal issues should they miss something serious. Nevertheless, finding the right balance between referring and reassurance is vital, as iatrogenic damage from imaging over-investigation may be a more common threat than legal proceedings (Mendelson and Montgomery, 2016).

\subsubsection{1 - The importance of enlisting sufficient clinical details by the referrers on their imaging requests}

The European Commission recognizes that the most common causes of the inefficient use of radiological resources are primarily coming from repeating imaging investigations which have already been done, requesting investigations when the imaging results are unlikely to affect the patients' diagnoses or clinical management, investigating too often, requesting the wrong investigations as well as failing to provide the appropriate clinical information that the requested imaging investigations should answer (European Commission, 2001). Imaging referrals are the primary means of communication between the 


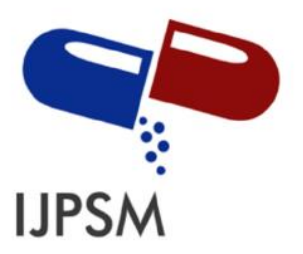

Georgiana Farrugia Bonnici, Int. Journal of Pharmaceutical Sciences and Medicine (IJPSM),

Vol.6 Issue. 4, April- 2021, pg. 92-115

ISSN: 2519-9889

Impact Factor: 3.426

requesting physicians and the reporting radiologists. Therefore, it is vital that every imaging request form is presented for reporting with sufficient clinical information (European Commission, 2001; Pitman, 2017). This measure will also increase the likelihood of generating better outcomes. There are various good quality attributes of valid imaging requests. Primarily, referrers should take into account the patients' radiation safety as well as the attributable diagnostic or clinical management values of the requested imaging modalities (European Commission, 2001; RCR 2017; Pitman, 2017). Secondly, a clear clinical question that the referrers want to be answered must be formulated whilst keeping in mind that such information will also be assisting the reporting radiologists in the interpretation of the imaging results, as well as in the completion of pertinent imaging reports (European Commission, 2001; RCR 2017; Pitman, 2017). Such requests, whether they are hand-written or electronically-based, should always be written or typed in a legible, unambiguous and complete manner; without any loss of content or meaning (European Commission, 2001; RCR 2017; Pitman, 2017). In cases of verbal request forms, particularly at times of clinical emergencies, the referrers must also ensure that there are no misunderstandings on the receiver's end, especially due to poor environmental conditions, such as noisy backgrounds or bad signals in the telephone lines (Pitman, 2017).

Sufficient demographic details, such as the patients' full name, the identity card number and the age, as well as the contact details of both the patients and the referrers are also necessary for the reporting radiologists to be able to unequivocally confirm their identities. Moreover, these details will also favour an unimpeded contact between the reporting radiologists, the referrers and the patients alike for the provision of results, the clarification of any imaging specifications, the correction of errors as well as clinical discussions (Pitman, 2017). If applicable, any patient preparation that is required prior to the imaging investigations to ascertain the highest imaging quality possible; such as fasting, pre-voiding, bowel emptying or the administration of oral or intravenous contrast-media should also be listed in the imaging request forms (Pitman, 2017).

\section{5 - The need for the development of imaging referral guidelines}

Clinical practice guidelines are systematically developed recommendations that are either evidencebased or expert-based, which seek to bridge the gaps between the processes of research and clinical practice (European Commission, 2001; RCR, 2017). Evidence-based guidelines are those which are formulated through rigorous scientific processes which mainly incorporate extensive literature searches with a summarization of all reliable findings which are retrieved from higher level sources of evidence (LoBiondoWood and Haber, 2017). When insufficient research on a particular topic is available, expert-based practice guidelines may also be developed (European Commission, 2001; RCR, 2017). The latter will focus on the derivation of a set of practice recommendations, which are primarily based on the professional opinions of a group of internationally or nationally known experts in the field; whom are usually supported with the limited research evidence that is currently available. A mixed-method approach may also be adopted to furtherly increase the strength, the quality and the validity of any newly developed clinical practice guidelines (European Commission, 2001; RCR, 2017).

Imaging referral guidelines, such as those issued by the Royal College of Radiologists in the United Kingdom (UK), the American College of Radiology (ACR), the European Society of Radiology (ESR), the National Institute of Health and Clinical Excellence (NICE), as well as the European Commission, are considered to be a sound method in aiding with the appropriateness of requesting imaging investigations. In 


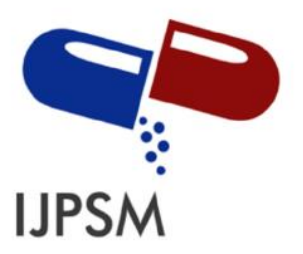

Georgiana Farrugia Bonnici, Int. Journal of Pharmaceutical Sciences and Medicine (IJPSM),

Vol.6 Issue. 4, April- 2021, pg. 92-115

ISSN: 2519-9889

Impact Factor: 3.426

fact, in Europe, such guidelines are mandatory by the Medical Exposures Directive (MED), which specifies that "member states must ensure that referral criteria, including radiation doses, are available for medical radiation exposures" (Malone, et al., 2012).

The level of effectiveness of the imaging referral guidelines may vary throughout several countries. For this reason, clinical compliance audits on the usage of imaging referral guidelines may be simple and effective tools that facilitate continuous improvements in the imaging referral patterns (Malone, et al., 2012). It has been established that such guidelines are most effective when they are developed and adapted to local situations and clinical settings (Malone, et al., 2012). In fact, a significant $13 \%$ reduction in the imaging referral rates of patients by family doctors was documented following the introduction of the first 1989 edition of the RCR guidelines (Malone, et al., 2012). Further studies employing this national feedback strategy have also demonstrated a sustained reduction in the inappropriate imaging referrals (Soye and Paterson, 2008; Malone, et al., 2012).

The need for achieving greater proportions of appropriate imaging referrals has become more evident in European countries over the past decade (Remedios, et. al., 2018). However, this process does come at an expense, for the development of imaging referral guidelines is both time-consuming and rather extensive as the methodology of evidence-based medicine should be strictly adhered to (Woo Kyoung, et al., 2016). They may also not be readily available in all countries, owing to various differences in social circumstances as well as in the health-care resources.

Leading radiologists from nineteen European radiation safety regulatory authorities, as well as international representatives from various health ministries have published a paper in which common barriers to improving the use of imaging referral guidelines were addressed (Remedios, et. al., 2018). In such study, a significant number of participants have claimed that imaging referral guidelines were not officially used in their countries. The most common reasons for the latter were either difficulties in the implementation of local policies on the use of imaging referral guidelines across different clinical departments, or due to issues relating to human and financial resources. On the other hand, other European countries such as Poland, Croatia, Russia and Sweden have managed to adopt translated imaging referral guidelines and promote their effective distribution across medical personnel (Remedios, et. al., 2018). In addition, the clinicians' awareness, acceptance and cooperation levels have also posed significant problems in several countries. To some extent, participants have reported that multi-disciplinary clinical meetings have enabled better education than imaging referral guidelines (Remedios, et. al., 2018). Participants have also remarked on the need for stronger legislation to provide better regulatory frameworks. This need was particularly evident in those countries where the doctors' mentality was to simply order rather than request imaging investigations. In such cases, the opportunity for radiologists' valuable input as to what could be the most appropriate imaging investigation was also being under-rated (Remedios, et. al., 2018).

\section{6 - The radiation safety awareness amongst medical practitioners}

It is important for all referring doctors to correlate the clinical complaints of their patients with the expected radiological outcomes in order to avoid the generation of false-positive or false-negative imaging findings. Unfortunately, it is often the case that when requesting any plain x-ray imaging investigations, radiologists are rarely consulted (Vilar-Palop, et al., 2018) possibly due to time constraints, busy schedules, or disregarding the need of a consultation from the referrer's end since it is considered as a very basic 


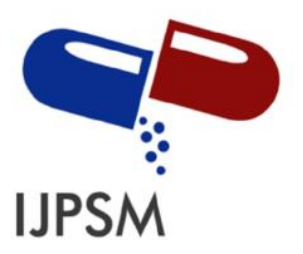

Georgiana Farrugia Bonnici, Int. Journal of Pharmaceutical Sciences and Medicine (IJPSM),

Vol.6 Issue. 4, April- 2021, pg. 92-115

ISSN: 2519-9889

Impact Factor: 3.426

imaging investigation. As a result, radiologists may also be interpreting the imaging reports with insufficient clinical information (Vilar-Palop, et al., 2018). Thereby, in an ideal clinical setting, both the radiologists and the referring doctors should closely collaborate with each other in an attempt to balance the possibility of detecting any treatable conditions against unnecessary imaging testing (Vilar-Palop, et al., 2018).

In a Norwegian study by Borgen, et al., (2010), the authors chose to explore the G.Ps' as well as the hospital physicians' radiation awareness, their consideration of radiation doses when referring, as well as their likelihood of using imaging referral guidelines. In this study, 71 hospital physicians at all grades and 77 G.Ps were asked to fill an anonymous questionnaire which was based on a preliminary literature review. It contained questions related to their weighting of radiation doses, the classification of the stochastic and the deterministic effects of ionizing radiation, whether the referrers knew of and had used any imaging referral guidelines, and if they had ever referred any patients for imaging that was unlikely to affect their management, as well as their approximate rate and reasons for such referrals (Borgen, et al., 2010).

A strength of this particular study is that it has a maximal response rate of $100 \%$ whereby all 148 invited clinicians have participated in the data collection process. In summary, several respondents from this particular study have under-estimated the radiation doses coming from high-dose imaging investigations, such as chest CT $(57.6 \%)$, abdominal CT $(52.7 \%)$ or para-nasal sinuses CT $(94.8 \%)$. The radiation doses coming from the thoracic spine and pelvic radiography were also underestimated by $18 \%$ to $22 \%$ of the referring physicians (Borgen, et al., 2010). Such findings correlate well with other findings from the studies by Soye and Paterson, (2008); Cesur, (2009), and Campanella, et al., (2017) who have also reported that throughout the years, the referrers did not properly understand the relative radiation associated risks. It has also been remarked that formal education regarding radiation safety is not given adequate importance by various medical training programmes for younger doctors to promote suitable understanding and long-term retention of knowledge (Park and Seung Jung, 2016)

Referring doctors in the study by Borgen, et al., (2010) have over-estimated the radiation doses too. Between $5 \%$ to $11 \%$ of doctors have even reported radiation coming from MRI and US investigations which do not utilize any form of ionizing radiation. These findings were also apparent in other similar studies by Soye and Paterson (2008) and Cesur (2009). Contrastingly, in the Italian study by Campanella, et al., (2017) the referrers have rightly indicated that both US and MRI are non-ionizing imaging modalities. On another note, only 34 out of 148 respondents ( $23 \%)$ in the study by Borgen, et al., (2010) have stated that they are aware of the terms 'deterministic and stochastic effects of radiation'. Similarly, physicians in a more recent study by Campanella, et al., (2017) have also over-estimated the teratogenic risks coming from ionizing imaging investigations. With respect to considering the weighting of the radiation dosing prior to the referrals for imaging, respondents have weighted the radiation doses as more important than the patients' wishes, but less important than the impact of the imaging on the patients' diagnoses, the clinical management or their future well-being (Borgen, et al., 2010). With respect to the use of the imaging referral guidelines, only half of the respondents have reported that they knew of referral guidelines. Moreover, only 76 respondents $(51 \%)$ had made use of such imaging referral guidelines in the past. Such findings compare well with the results from the recent study by Remedios, et. al., (2018) which were already previously discussed.

As many as $88 \%$ of the G.Ps and $83 \%$ of the hospital physicians have admitted to sending requests for imaging that would be unlikely to alter the clinical management of their patients (Borgen, et al., 2010). 


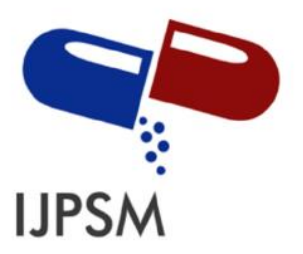

Georgiana Farrugia Bonnici, Int. Journal of Pharmaceutical Sciences and Medicine (IJPSM), Vol.6 Issue. 4, April- 2021, pg. 92-115

ISSN: 2519-9889

Impact Factor: 3.426

Furthermore, family doctors have reported a slightly higher percentage of such referrals (a median of 10\%) than hospital physicians $(5 \%)$. Their top reasons for doing so have included that "normal findings will reassure their patients" and to "give their patients the feeling of being taking seriously". Other less important reasons being mentioned have also included: "Patient or relatives expectations", "lack of time" or to "compensate for insufficient clinical examination". Similar reasons for over-investigating were also brought up by Mendelson and Montgomery (2016) in another research paper.

The study by Borgen, et al., (2010), has also revealed that the respondents have limited radiation safety awareness and that $80 \%$ of these physicians did not use any imaging referral guidelines throughout the course of their respective medical careers. Interestingly, those respondents who have weighted a lower radiation dose when referring have also reported less imaging guidelines use and have later explicitly admitted to requesting more imaging referrals that were unlikely to affect the clinical management of their patients. In such study, the unforeseen response period to the authors' questionnaire has generated more valid data on the radiation safety awareness than could be achievable in a postal or an e-mail survey (Borgen, et al., 2010). However, the use of questionnaires has inherent limitations. In this study, the respondents' self reports on their own practices should be interpreted with care, as they may be biased by their wishes to answer correctly; which is also known as the Hawthorne effect (Borgen, et al., 2010). Also, a fairly representative sample was not achieved since it was not possible for the authors to randomly select respondents from their respective professional cohorts (Borgen, et al., 2010).

Another group of Italian researchers, Campanella, et al., (2017) have also sought to investigate the level of doctors' awareness about the patients' exposure to ionizing radiation during common radiological procedures. A total of 419 Italian physicians, 114 of whom were G.Ps, have answered a semi-structured questionnaire which has consisted of 26 multiple-choice questions about radiation safety, the awareness of radiation imaging doses as well as the deterministic and the stochastic effects of ionizing radiation (Campanella, et al., 2017). The authors have then matched all the correct answers to quantify their respondents' level of awareness on each topic of interest. Their scoring system was based on the data that were published in the Annual Report of the Italian Agency for the Environmental Protection, as well as the Council Directive 2013/59/EURATOM (Campanella, et al., 2017). It has been estimated that 364 doctors $(65.9 \%)$ regularly request radiological investigations mostly in accordance with their clinical judgements. Contrastingly, $25.9 \%$ of doctors have stated that they do consult with radiology specialists at their disposition, prior to referring some of their patients for imaging investigations (Campanella, et al., 2017). Such findings also concur with the findings that were reported by Remedios, et. al., (2018).

Almost half of the 202 (48.2 \%) doctors in this Italian study have also claimed that they have previously attended formal radiation safety courses, either throughout the course of their medical school journey or during their professional careers (Campanella, et al., 2017). $22.9 \%$ of these doctors have also registered interest in receiving further training on any current updates in radiation safety and imaging referring processes. The amount of correct responses to the questions assessing the radiation safety awareness were $62.3 \%$. It has been noted that higher mean scores were coming from radiologists $(73.9 \%)$, possibly because they are more experienced in dealing with specific conditions that necessitate investigation via diagnostic or interventional radiography. Such finding also concurs with the research evidence that has been previously provided by Soye and Paterson (2008) who have also reported that the greater awareness of radiation safety by radiologists might plausibly be in relation to the specific training received during their radiology residency. In comparison to the previously discussed studies by Soye and Paterson, (2008); Cesur, (2009) (C) 2021, IJPSM All Rights Reserved, www.ijpsm.com 


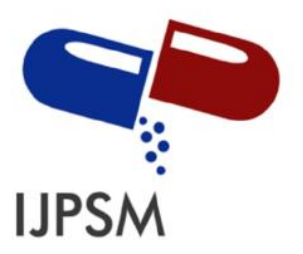

Georgiana Farrugia Bonnici, Int. Journal of Pharmaceutical Sciences and Medicine (IJPSM), Vol.6 Issue. 4, April- 2021, pg. 92-115

ISSN: 2519-9889

Impact Factor: 3.426

and Borgen, et al., (2010), referrers in this study have also under-estimated the radiation doses coming from most imaging modalities. In addition, only $3.3 \%$ of the respondents were able to correctly evaluate the radiation doses in all of the five imaging modalities (Campanella, et al., 2017). In terms of the organ sensitivity to the radiation exposures, approximately half of the respondents (46.0\%) have falsely believed that the thyroid gland is the most radio-sensitive tissue. On the other hand, $86.3 \%$ of the respondents were fully aware that children were more sensitive to ionizing radiation than adults or elderly persons (Campanella, et al., 2017). Nonetheless, such findings should be interpreted with caution as this Italian study shows some limitations that could influence results. Firstly, the very low response rate of $10.5 \%$ might have introduced a selection bias (Campanella, et al., 2017). Secondly, the web-based methodology could have led to an under-representation of those doctors with limited access to the Internet services at the time of the data collection; thus contributing to further sampling bias.

\section{7 - The use of imaging referral guidelines within medical communities}

The objective of another group of researchers, Remedios, et. al. (2014) was to develop a Europeanbased study on imaging referral guidelines in all European Union (E.U.) member states, with the aim of identifying any potential major issues as well as the important differences in practices between several E.U. member states (Remedios, et. al. 2014).

A web-based questionnaire was drafted by the Royal College of Radiologists, together with other members of the Referral Guidelines Project Consortium. A total of 80 responses were received from the national representatives of all 30 countries being surveyed; 32 of whom being from the representatives of national radiological societies, whilst another 20 responses corresponding to the representatives from national nuclear medicine societies. The remaining 28 responses were registered from the representatives of national competent authorities in this field.

With regards to the questions about the availability of imaging referral guidelines in European countries, 70 $\%$ of responders have stated that they are aware that there is a legal requirement for such guidelines; including DRLs, as well as a radiation dose limit for every patient (Remedios, et. al. 2014). On the other hand, 5 responders $(4 \%)$ have stated that they were uncertain as to the existence of such legislations. Such findings concur with a previous study by Malone, et al., (2012) whereas it was also reported that the practices of radiation safety were variably given less priority across multiple countries. It was then confirmed by the authors at a later stage, that in fact, all E.U. member states have such a legal requirement in place (Remedios, et. al. 2014). Moreover, $60 \%$ of the international respondents in this study were aware of the presence of imaging referral guidelines. These findings correspond well with similar findings that were delineated from other papers, such as those by the Royal College of Radiologists, (2017); as well as the French, Austrian, Belgian, Czech, Danish, Finnish, Italian, Slovak, Dutch, Spanish and Swiss Radiological Societies (Austrian Society of Nuclear Medicine and Molecular Imaging, 2018; Belgian Society for Nuclear Medicine, 2018; Czech Society of Nuclear Medicine, 2018; Dutch Radiological Society, 2018; Italian Association of Nuclear Medicine, 2018; Radiological Society of Finland, 2018; Romanian Society of Nuclear Medicine, 2018; Slovak Society of Nuclear Medicine and Radiation Hygiene, 2018; Société Française de Radiologie, 2018; Spanish Society Radiology, 2018; Swiss Society of Nuclear Medicine, 2018; The Danish Society of Radiology, 2018). 


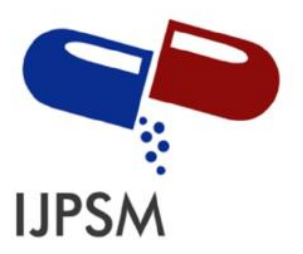

Georgiana Farrugia Bonnici, Int. Journal of Pharmaceutical Sciences and Medicine (IJPSM), Vol.6 Issue. 4, April- 2021, pg. 92-115

ISSN: 2519-9889

Impact Factor: 3.426

The majority of the respondents in the study by Remedios, et. al. (2014) have also indicated that the imaging requests being sent by family doctors are more likely to be for plain radiography, contrast radiography or US, but fewer for CT, MRI, RNI or interventional radiology when compared to the imaging referrals being made by hospital specialists who are more likely to request the latter. Respondents have also indicated that the most common modality for which a patient could self-present in general practice was primarily for US, followed by plain radiography and MRI respectively (Remedios, et. al. 2014). Such findings were also evident in other studies, namely those by Soye and Paterson, (2008); Cesur, (2009), as well as Borgen, et al., (2010). This could be due to the fact that such low-dose imaging procedures are considered to have lesser risks in relation to the patients' radiation exposures.

It is also notable that imaging referral guidelines are present in most European countries. Nevertheless, respondents from fourteen countries have claimed that imaging referral guidelines are either still in the process to be developed nationally or else to be adapted with modifications from other reputable sources (Remedios, et. al. 2014; Remedios, et. al. 2018). The approximate duration of these reviewing cycles vary across different countries, mainly from three to four years to greater than six years (Remedios, et. al. 2018). This triangulates well with the findings from another study of the same year by Sa Dos Reis, et al., (2018), whereby a vital strategy that was employed to reduce the numbers of non-indicated ionizing imaging examinations that were being performed on a daily basis, was to develop high quality imaging referral guidelines that are well-suited to cater for a wider variety of clinical patient encounters. This measure has ensured that such guidelines will be able to aid the respective medical communities accordingly, most especially at times of clinical difficulty (Sa Dos Reis, et al., 2018).

Imaging investigations involving ionizing radiation; mainly those relating to plain radiography and nuclear medicine procedures were included in a greater majority of imaging referring guidelines (83-92\%), whereas the non-ionizing radiology modalities such as US or MRI were present in approximately $75 \%$ of such guidelines. Separate guidelines for children and pregnant women are also found, but these tend to cover fewer clinical conditions (Remedios, et. al. 2014; Remedios, et. al. 2018). Most radiological guidelines tend to focus on the clinical presentations and cover multiple groups of diseases and medical conditions for adults, including those related to neoplasms, trauma, the cardio-thoracic system, the gastrointestinal system, the neurological system, the musculo-skeletal system and the uro-genital system (Remedios, et. al. 2014; Remedios, et. al. 2018).

Regarding the formatting and the dissemination of the national imaging referring guidelines, almost all guidelines are available in downloadable digital versions which may be routinely circulated to family doctors, emergency physicians as well as hospital-based specialists (Remedios, et. al. 2014; Remedios, et. al. 2018). Reinforcement of such guidelines is advocated through periodical reminders or via educational messages by most of the radiological societies (Remedios, et. al. 2014; Remedios, et. al. 2018). Respondents from the two studies by Remedios, et. al. (2014) and Remedios, et. al. (2018), strongly support the use of local internal and external clinical audits to monitor the usage of imaging referral guidelines. Comparingly, in another paper, the European Association of Nuclear Medicine (EANM), et al., (2016) has also highlighted that the approach to improve the use of ionizing radiation in medicine by solely formulating fundamental research would lack impact unless being translatable to everyday clinical practice. Therefore, it is essential for the research study results to be easily accessible to the referrers, in order to implement the methodologies developed. It is also beneficial that the same level of importance is placed on educating both the medical and 


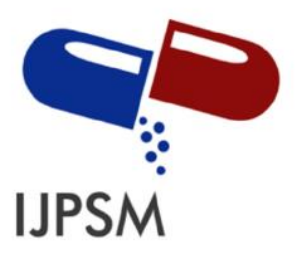

Georgiana Farrugia Bonnici, Int. Journal of Pharmaceutical Sciences and Medicine (IJPSM), Vol.6 Issue. 4, April- 2021, pg. 92-115

ISSN: 2519-9889

Impact Factor: 3.426

the allied health-care professionals to guarantee a direct clinical impact and to ensure high-level, standardised medical care and radiation safety.

\section{8 - The medical doctors' awareness about imaging justification and the optimisation of radiation safety}

Radiation safety in medicine revolves around the processes of justification and optimisation. The extent of ionizing radiation use in radiology has become a matter of concern for many reasons, such as the appropriateness of the examinations being requested as well as the population radiation doses, the individual effective radiation doses along with unsustainable financial issues and excessive departmental work-loads (Faulkner, 2008; Malone, et al., 2009; Malone, et al. 2012).

When an investigation that involves the use of ionizing radiation is proposed, the anticipated benefits to the management of the patients are usually recognisable. On the other hand, the risks of adverse consequences are often difficult to estimate, or else require statistical techniques to infer. Nonetheless, in both its 1990 and 2007 recommendations, the International Commission on Radiological Protection (ICRP) has stated that "any decision that alters the radiation exposure situation should do more good than harm" (Malone, et al., 2012). Notably, there are three levels at which imaging justification operates. Primarily, the use of ionizing radiation in medicine is accepted as doing more good than harm, so its overall justification is more often than not taken for granted (Malone, et al., 2009; Malone, et al. 2012). Secondly, a specified procedure with a specified objective is defined and justified, with the question of whether that procedure will aid in the diagnosis or in the management of a particular case presentation (Malone, et al., 2009; Malone, et al. 2012). Finally, the application of the procedure to an individual patient must be also justified (Malone, et al., 2009; Malone, et al. 2012).

Ample reasons have been pointed out as to why the principle of justification may not be so successfully adhered to and these may include: a feeling among doctors that there is little practical action that may be taken to improve the situation; the continuous use of radiology for the purpose of defensive medicine as well as significant communication failures between medical professionals over a prolonged period of time (Malone, et al., 2012). While these factors are all understandable, it is not justifiable to continue to expose patients to the consequences of unnecessary risks. It has also been established that successive approaches towards the communication of relative radiation risks to both patients and health-care professionals have not been particularly effective (Malone, 2008; Malone, et al., 2009; Malone, et al., 2012). This suggests the need for developing better ways of skilled, trusted communication about the relative radiation risks. The requirements for improvements in communication may include: giving due consideration to any previous examinations and their relationships with the most recent ones; the use of preparatory leaflets for patients to allow for the assimilation of thoughts prior to entering the consultation rooms, which will stimulate an environment to ask relevant questions to their referring physicians; the use of a clear, non-technical approach to presenting the expected radiation doses and risks by trustworthy health-care professionals as well as the recognition that the amplification of relative radiation risks may occur.

It is also of interest to note that some literature sources suggest that $20 \%$ to $77 \%$ of radiographical examinations may turn out to be inappropriate. These ranges could be alarming in the long run, especially when applied in those examinations with higher effective radiation doses (Oikarinen, et al., 2009; Almen, et al., 2009; Malone, et al., 2012). Moreover, referrers may have limited awareness of the actual radiation 


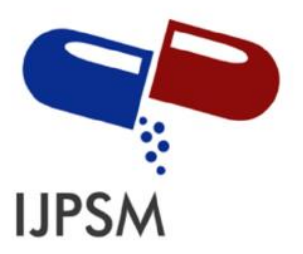

Georgiana Farrugia Bonnici, Int. Journal of Pharmaceutical Sciences and Medicine (IJPSM),

Vol.6 Issue. 4, April- 2021, pg. 92-115

ISSN: 2519-9889

Impact Factor: 3.426

doses and the risks involved behind requesting certain radiological examinations (Rehani, 2017; Campanella, et al., 2017). For example, some publications have identified that few doctors are actually familiar with the units which are used to specify the amount of radiation that is being received by their patients (Faulkner, et al., 2008; Campanella, et al., 2017). This deficiency could potentially lead to an underestimation of the radiation hazards involved.

Certain studies indicate that less than $50 \%$ of physicians in well-established teaching centres are aware of the presence of imaging referral guidelines that could be consulted when in doubt about the radiological indications for common conditions (Soye and Paterson; 2008; Malone, 2008; Malone, et al., 2009; Malone, et al., 2012). Under such circumstances, patients may not fully understand all the potential risks that are involved behind radiological investigations (Bedetti, et al., 2008, Malone, et al., 2012). Patients can also routinely end up receiving radiation doses that are larger than expected, when compared to the DRLs (Malone, et al., 2012). These circumstances shed light onto another quest; that is the need for physicians to be aware of the actual patients' wishes in the imaging justification processes. Needless to say, the active participation of the patients also requires responsible medical doctors who have an obligation to assist their patients in balancing the immediate risks of their presenting conditions against the long-term risks of the ionizing radiation doses which are involved in the requested imaging procedures (Rehani, 2017).

More initiatives are necessary to be able to develop universal, practical and accountable approaches to the implementation of imaging justification in day-to-day clinical practice (Malone, et al., 2012). In fact, in order to ensure an effective implementation of imaging justification, referrers needs to primarily ensure that those patients who are being referred for radiological examinations do really need them for their clinical management or treatment purposes. Secondly, one also needs to take into consideration the clinical auditing of the effectiveness of all the referring processes. Finally, it is also important to think about ways of devising means of effective communication about the relative radiation risks to the patients and doctors alike (Malone, et al., 2012).

\section{9 - The over-use of ionizing imaging investigations: How common is this in general practice?}

Oftenly, the over-use of medical imaging services can be measured directly via comparing the appropriateness of the imaging referrals against evidence-based clinical guidelines (Brownlee, et al., 2017). However, one must also acknowledge that at times such gold-standard guidelines will not include all the information that is needed to comprehend the whole spectrum of the clinical conditions for which the imaging tests are required (Brownlee, et al., 2017). It has also been demonstrated that when the clinical details in the patients' medical records were reviewed in conjunction with their imaging referrals, the nonclinically indicated rate of examinations will be reduced (Rawle and Pighills, 2018).

As has been previously discussed, one should not dismiss the fact that there is room for improvement when it comes to safeguarding the patients' rights in relation to the reduction in the cumulative effective radiation doses that are received from inappropriate imaging investigations (Almén, et al., 2009; Oikarinen, et al., 2009; Greenberg, et al., 2014). One must also look into the social phenomenon that there may be other situations where referring physicians might ask for imaging investigations simply to be able to reassure patients, although there is no real suspicion of disease (Brownlee, et al., 2017). Although these situations may be habitual in daily clinical practice, they are still to be considered as inappropriate as the consequences of the over-use of imaging tests may range from increased costs and longer waiting lists to over-diagnoses 


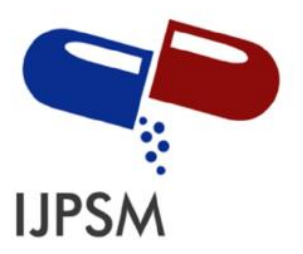

Georgiana Farrugia Bonnici, Int. Journal of Pharmaceutical Sciences and Medicine (IJPSM), Vol.6 Issue. 4, April- 2021, pg. 92-115

ISSN: 2519-9889

Impact Factor: 3.426

and medical clinical cascades, along with unnecessary radiation exposures (Hamada and Fujimichi, 2014; Brownlee, et al., 2017; Lumbreras, et al., 2018).

Unfortunately, most of the available studies that sought to analyse the over-use of imaging investigations have mainly focused on costly, high-radiation dose imaging techniques, such as CT scanning (Almén, et al., 2009; Lehnert and Bree, 2010) However, in reality, these techniques usually account for only up to $20 \%$ of all imaging tests being carried out in routine clinical practice (Lehnert and Bree, 2010). In certain care centres, requests for high-end imaging modalities require vetting by a radiologist prior to being done (European Commission, 2015). Conversely, plain x-rays have been less studied in relation to over-use, despite amounting to over $70 \%$ of the total imaging referrals (Malone, et al., 2012); possibly due to their attributed lower radiation effective doses. Additionally, current evidence strongly suggests that very few family doctors are using imaging referral guidelines to assist them in the processes of imaging justification (Vilar-Palop, et al., 2018). Regardless of the respective radiation doses, the potential detrimental effects of the high prevalence use of inadequate low-dose radiation imaging tests are also ideally to be included in the findings of those research studies estimating the over-use of imaging tests (Vilar-Palop, et al., 2018).

In a recent Spanish study by Vilar-Palop, et al., (2018), the authors sought to assess if the referring physicians from two different Spanish medical centres will choose the most appropriate ionizing imaging investigations for various given clinical conditions, according to four gold-standard imaging referral guidelines. They have also estimated the total radiation effective doses which are being received by patients, as well as the brief health-care costs there are associated with all the imaging referrals being analyzed.

Data were retrospectively collected from the radiology information systems (RIS) of both Spanish medical centres (Vilar-Palop, et al., 2018). The appropriateness of the 2022 imaging tests which were reviewed was determined by five expert researchers who are trained in the use of the following four guidelines: The Radiation safety 118: Referral Guidelines for Imaging; The American College of Radiologists (ACR) Appropriateness Criteria; the 'Do Not Do' Spanish Radiological Society guidelines, as well as the Guidelines by the National Institute for Health and Care Excellence (NICE). More than half of the imaging referrals were received from several outpatients departments, including primary care clinics $(1221,60.4 \%)$, 546 referrals $(27.0 \%)$ from the casualty departments, as well as 255 inpatients ward referrals (12.6\%). The most common indication for imaging in this study is neoplasm $(476,23.5 \%)$, followed by diseases of the musculoskeletal system $(446,22.1 \%)$ and diseases of the respiratory system $(300,14.8 \%)$. In total, plain radiography has accounted for 1417 (70 \%) of the total referred imaging tests (Vilar-Palop, et al., 2018).

When compared to the selected imaging referral guidelines, almost half of the 2022 imaging requests reviewed were deemed as appropriate $(967,47.8 \%), 634$ imaging requests $(31.4 \%)$ were considered as inappropriate, whilst 94 imaging requests $(4.6 \%)$ were deemed as being inappropriate due to repetition, and 169 imaging requests $(8.4 \%)$ were listed as not adequately justified (Vilar-Palop, et al., 2018). For the remaining 158 imaging requests $(7.8 \%)$, the clinical scenarios were not included in the referral guidelines so they could not be compared accordingly (Vilar-Palop, et al., 2018). Such findings compare well with those that have been reported by Almén, et al. (2009) as well as those by Lehnert and Bree (2010); in which 19.3 $\%$ and $26.0 \%$ of the imaging referrals were also not justified, respectively. Additionally, inpatients (59.6 $\%)$ were more likely to have an imaging request being classified as appropriate than outpatients (46.4\%) or those patients who were referred from the casualty departments $(45.4 \%)$. On the other hand, inpatients were also more likely to have an inappropriate imaging request due to repetition (13.3\%). 


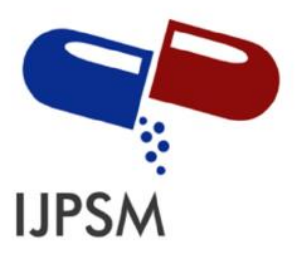

Georgiana Farrugia Bonnici, Int. Journal of Pharmaceutical Sciences and Medicine (IJPSM),

Vol.6 Issue. 4, April- 2021, pg. 92-115

ISSN: 2519-9889

Impact Factor: 3.426

The total cumulative effective dose that is associated with the 2022 imaging referrals in this particular study is of $4482.8 \mathrm{mSv}$ (Vilar-Palop, et al., 2018). More than half of the effective cumulative dose (2446.1 mSv, $54.2 \%)$ is associated with appropriate imaging tests. However, $19.6 \%$ (884.9 mSv) is coming from inappropriate referrals, when compared to the gold-standard imaging referral guidelines (Vilar-Palop, et al., 2018). Such findings compare well with another study by Rawle and Pighills (2018), whereas the analysis of all imaging referrals has indicated that only a quarter $(24.7 \%)$ of total imaging examinations have met the referring criteria for their diagnostic imaging pathways. The remaining $75.3 \%$ of imaging investigations have only partially met, or did not meet the imaging referral criteria at all (Rawle and Pighills, 2018; Sa Dos Reis, et al., 2018). Apart from being attributable to a lack of awareness of the imaging referring criteria by the referring clinicians, these authors have also concluded that such results within a hospital setting could have also been favoured by the radiographers not complying with the imaging justification requirements.

The recent Spanish study by Vilar-Palop, et al., (2018), also investigates the current occupational backgrounds of the referring physicians so their findings can also be specifically applied to general practice. In fact, the authors of this study have concluded that G.Ps were less likely to order appropriate imaging investigations than those hospital physicians who were working in different clinical specialty departments. Specifically, $40.4 \%$ of the total imaging referrals coming from general practice were considered as inappropriate, whilst a lower total rate of inappropriate imaging referrals $(18.9 \%)$ were recorded from hospital clinical specialists. Vilar-Palop, et al., (2018) further argued that a possible reason for this particular trend is that patients attending general practice clinics were more prone to present with diffuse symptoms when compared to those visiting specialized care clinics; which could in turn, instigate over-investigation. Additionally, it is also possible that there is a greater element of ambiguity in the clinical terms which are being used by the G.P. referrers to describe these diffuse symptoms on their imaging referrals. Unfortunately, such non-specific criteria are unlikely to be directly catered for in the strict imaging referral guidelines; which could possibly lead to an under-estimation of the percentage of the appropriateness of the imaging referrals by G.Ps.

In the study by Vilar-Palop, et al., (2018), there is also a smaller percentage (4.6\%) of imaging tests that were considered as being inappropriate due to repetition within a non-indicated time-frame. Ideally, the referring doctors should have an easy access to all their patients' medical and radiological histories before requesting new investigations (Rehani, 2017). Nevertheless, in the setting of general practice, this may not always be possible since patients might be visiting different G.Ps for emerging complaints. In such cases, health information systems (HIS) typically come in handy in reviewing a particular patient's profile; albeit there are usually access-control mechanisms in place that forbid the accesses to specified information to those referrers who are working outside the dedicated access-zones (Rehani, 2017). It is also known that some available guidelines do not always explicitly state the appropriate timing for imaging, including when it would be considered as clinically relevant to repeat an imaging investigation. In such situations, local medical protocols in combination with the professional's clinical judgement should also be sought (Tahvonen, et al., 2013).

The study by Vilar-Palop, et al., (2018) is a retrospective analysis of existing medical records which is governed by certain limitations. To start with, such imaging referral guidelines, despite being up to date, do not cover all real-life clinical scenarios. In fact, the authors admit to not being able to completely assess the appropriateness of some imaging investigations $(7.8 \%)$, particularly those relating to either neoplasms or trauma. Alternatively, the authors have decided to classify such cases as not included in the guidelines so (C) 2021, IJPSM All Rights Reserved, www.ijpsm.com 


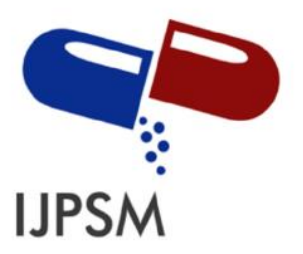

Georgiana Farrugia Bonnici, Int. Journal of Pharmaceutical Sciences and Medicine (IJPSM),

Vol.6 Issue. 4, April- 2021, pg. 92-115

ISSN: 2519-9889

Impact Factor: 3.426

that they would not be misleadingly counted either as appropriate or as inappropriate. Moreover, the authors have solely based their analysis on the available data being listed on the imaging referral requests, so in practice, they may have been unaware of some other missing, but rather relevant data in the patients' medical history that collectively could have merited the indication for a more valid imaging referral. Indeed, the authors' approach to define appropriateness from previously published gold-standard imaging referral guidelines is simple, but it is also limited, in the sense that this process does not allow them to discriminate between each particular patient's situations.

\subsection{1 - The patient-centred outcomes related to the use of radiological services in primary care}

Undoubtedly, radiological services fulfill multiple roles in primary care; including the screening, the diagnosis and the monitoring of diseases (Zigman Suschland, et al., 2019). In order to promote the judicious use of imaging services and to facilitate the development of tools which may enable the referring physicians to better understand their patients' experiences of these investigations, it is vital that one also takes into account various patient-centered outcomes. Such outcomes typically range beyond the bio-medical aspects to the cognitive, the emotional, the social, the financial, the physical and the behavioral effects related to the requested imaging tests (Zigman Suschland, et al., 2019; Lim, et al., 2019).

In the multi-centred, qualitative study by Zigman Suschland, et al., (2019), the diagnostic insights which were obtained from the imaging tests were oftenly regarded as valuable outcomes by patients in primarycare settings. In addition, these patients were also relieved by learning that their symptoms were not being caused by something serious (Zigman Suschland, et al., 2019, Lim, et al., 2019). On the other hand, negative impressions, such as excessive worrying or frustration were also registered from those patients whose imaging investigations were either indeterminate or inconclusive (Zigman Suschland, et al., 2019; Lim, et al., 2019). Such conclusions concur with the earlier findings by Moynihan, et al., (2012) and Mendelson and Montgomery (2016), whereby the false positive results as well as the false negative results that have emerged from imaging investigations have also led patients to either false alarm or inappropriate reassurance. Moreover, these patients have also identified a number of direct physical experiences relating to the actual performance of the imaging tests. Some general discomforts that may be experienced by patients during radiography services may range from aches and pains that are typically associated with holding certain radiographic positions, excessive background noises or feelings of claustrophobia (Zigman Suschland, et al., 2019; Lim, et al., 2019).

Back pain is invariably one of the most common reasons for referrals to primary health-care centres. In comparison to the studies by Moynihan, et al., (2012), Mendelson and Montgomery (2016) as well as Zigman Suschland, et al., (2019) which have already been previously discussed; Lim, et al., (2019) in an extensive, systematic literature review also highlight that one of the strongest interests for patients seeking medical advice about back pain is to obtain a definitive diagnosis. Moreover, such patients whom were mainly based in the U.K., were frequently frustrated with receiving generic statements from their doctors pertaining solely to the age-related wear and tear as means to justify their chronic, debilitating back pain symptoms (Lim, et al., 2019). Yet, this mentality heavily contradicts the current evidence-based management of back pain, which strongly advises against the routine use of back imaging investigations in the absence of the suspicion of any red flags; such as infection, metastasis or fractures (European Commission, 2001, RCR, 2017, Lim, et al., 2019). Imaging in such circumstances has long been considered to be of low diagnostic value and also serves as a potential driver for increased relative radiation risks and 


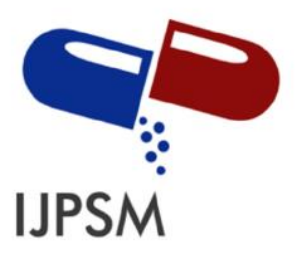

Georgiana Farrugia Bonnici, Int. Journal of Pharmaceutical Sciences and Medicine (IJPSM), Vol.6 Issue. 4, April- 2021, pg. 92-115

ISSN: 2519-9889

Impact Factor: 3.426

health-care costs (European Commission, 2001, RCR, 2017, Lim, et al., 2019). These findings clearly highlight the mismatch between the patients' perceived benefits of health information, in comparison to their doctors' professional advices on the evidence-based management of back pain (European Commission, 2001; Mendelson and Montgomery, 2016; RCR, 2017; Zigman Suschland, et al., 2019; Lim, et al., 2019).

This systematic literature review has some limitations. Primarily, the authors have declared that the sources of information that they have referenced about back pain; such as those dealing with the patients' identified needs for health information, have been extrapolated from heterogeneous studies which were evaluating different objectives in several non-comparable study groups (Lim, et al., 2019). Thus, it is possible that some areas of information may have not been identified within this systematic review. Furthermore, most of the studies that were included in this literature review were performed in the U.K., so it remains unclear as to whether these findings could be generalised to other countries with potentially different ethnicities, economies or health-care systems (Lim, et al., 2019).

Some effective interventions that have already been previously studied in order to improve the mitigation of the patients' unhelpful beliefs include the ability of the referrers to effectively communicate the role of imaging to their patients in layman's terms in a way that provides maximal verbal reassurance and highlights a meaningful management plan; even if within a limited time span (Mendelson and Montogomery, 2016; Lim, et al., 2019). Furthermore, the use of simple patient education videos or booklets that could be used to transfer clear, consistent and trustworthy information whilst the patients are still in the waiting areas of both primary care clinics as well as hospital settings have also registered promising results (Lim, et al., 2019). This valuable information could then be further substantiated by their clinicians throughout their medical consultations, whilst specifically tailoring the transfer of further information in relation to their patients' age, lifestyle and occupational statuses. It has also been reported that patients are also interested in getting to know more about their non-pharmacological treatment options; such as physiotherapy, alternative pain remedies and other patient-tailored support services (Zigman Suschland, et al., 2019; Lim, et al., 2019).

\subsection{0 - An insight into the specific patient-related factors and disease criteria leading to the over-use of medical imaging investigations in clinical practice}

\subsection{1 - Gender and age-related factors}

In the Spanish study by Vilar-Palop, et al., (2018), women (45.9\%) were less likely to be sent for imaging referrals which are being considered as appropriate, than men (50.4\%). Such findings compare well with those by Redondo-Sendino, et al. (2016); in claiming that women tend to make more use of their G.P. services and also have a greater likelihood to present with non-specific complaints than men. Thereby, they are also more prone to be referred for diagnostic imaging investigations. Ashurst, et al., (2014) have also argued that gender differences may also affect the overall presentation of diseases, the risks of impromptu testing as well as the diagnostic yields of imaging investigations.

Furthermore, in the study by Vilar-Palop, et al., (2018), patients older than 75 years (54.3\%) were more likely to be referred for appropriate imaging requests than their younger counter-parts; particularly those patients who were younger than 47 years of age $(44.7 \%)$. This trend could be due to the need of G.Ps to follow up on the presence of chronic problems in the elderly, as opposed to the acute presentations in younger patients, which are often resolved in a shorter time span. 


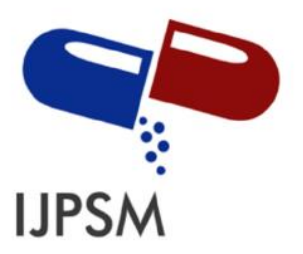

Georgiana Farrugia Bonnici, Int. Journal of Pharmaceutical Sciences and Medicine (IJPSM),

Vol.6 Issue. 4, April- 2021, pg. 92-115

ISSN: 2519-9889

Impact Factor: 3.426

\subsection{2 - Disease-related factors}

Patients with respiratory diseases were more likely to have an imaging request being classified as appropriate (70.8\%) compared to other patients whose chief complaints were in other body systems (VilarPalop, et al., 2018).

It was also noted that the indications of certain imaging referrals may vary according to the nature of the suspected diseases by the referring doctors. For example, those imaging tests that were ordered for patients with a known respiratory disease were more likely to be appropriate than those of whom were referred for a routine, pre-operative chest x-ray. Despite the fact that the European Commission's Radiation safety 118: referral guidelines for imaging (2001), advise against the bookings of pre-operative chest $\mathrm{x}$-rays for elective surgery patients without the presence of any underlying significant cardio-respiratory pathology, 69\% of all pre-operative chest $\mathrm{x}$-rays referrals being analysed in the study by Vilar-Palop, et al., (2018) were considered as not indicated.

Diseases of the gastrointestinal system were also associated with a total higher percentage rate (52\%) of inappropriate imaging examinations (Vilar-Palop, et al., 2018). The authors have implied that this observed trend could be partly due to the fact that a significant amount of plain abdominal radiographs were requested in non-trauma emergency patients; a practice that is not routinely recommended in the RP 118 imaging referral guidelines (European Commission, 2001) because it is much less likely to affect the patients' management.

Comparably, plain x-ray investigations pertaining to the musculoskeletal system were also connoted with a higher rate of non-indication as per the imaging referring guidelines. Rawle and Pighills (2018) sought to analyse the justification of a sample of plain x-ray imaging examinations that were performed in the emergency department of a regional hospital. The authors have retrieved a total of 186 referrals for general $\mathrm{x}$-ray imaging, with imaging of the ankle, the knee and the shoulder representing the three most frequently performed $(51.6 \%)$ radiographic examinations. The corresponding number of examinations that have actually met the clinical requirements for referral were $9 \%$ for the ankle examinations, $26 \%$ for the knee examinations and $46 \%$ for the shoulder examinations respectively (Rawle and Pighills, 2018; Sa Dos Reis, et al., 2018). Such study has suffered from the limitation of a single-centre approach and invariably, by the analysis of a smaller sampling size. In addition, a single reviewer with thirteen years of experience in general radiography has identified whether an imaging pathway existed for each referred examination, and has then determined whether such imaging investigations were justified. Hence, the reviewer's experience in the justification practices or his level of agreement with the diagnostic imaging pathways may have biased the final interpretation of the results. Moreover, the study's internal validity could also be questioned (Rawle and Pighills, 2018; Sa Dos Reis, et al., 2018).

It has also been reported that practising doctors may either be inadequately trained or lacked confidence in the management of chronic, musculoskeletal conditions (Lim, et al., 2019). Moreover, further concerns have been expressed in relation to the referrers experiencing difficulties in the implementation of a bio-psychosocial approach to low back pain management (Lim, et al., 2019). These deficiencies could also be contributing to the provision of lower value health-care services, threatened therapeutic doctor-patient relationships as well as the promotion of the over-use of medical imaging investigations; which may not necessarily have favourable risk-to-benefit ratios. Thus, various new approaches to CME; such as group- 


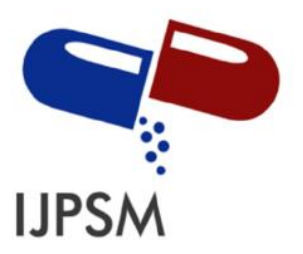

Georgiana Farrugia Bonnici, Int. Journal of Pharmaceutical Sciences and Medicine (IJPSM),

Vol.6 Issue. 4, April- 2021, pg. 92-115

ISSN: 2519-9889

Impact Factor: 3.426

based clinical training sessions or the interactive approaches to virtual learning have been used successfully in conjuction with the imaging referral guidelines, as well as other traditional methods of disseminating educational materials amongst medical personnel (Lim, et al., 2019).

The evaluation of bone or soft tissue tumours may be a challenge to orthopaedic surgeons and G.Ps alike. There may also be limited guidance on what should be done for these kind of cases, prior to the patients' referral for specialized care (Miller, et al., 2015). Despite that G.Ps may have the opportunity to request advanced imaging modalities; including MRI, CT, bone scans, US, and PET scans; each of these tests will only prove useful if being requested for the correct clinical indications (European Commission, 2001; Miller, et al., 2015; RCR 2017).

The excessive use of medical imaging services has been targeted as a substantial contributor to overspending in many, universal health-care systems (Miller, et al., 2015). Hence, in the study by Miller, et.al., (2015), eight orthopaedic oncologists have sought to determine whether the requested imaging investigations were truly being helpful in the oncology patients they have been personally evaluating. The criteria that were used by these eight orthopaedic oncologists to determine if an imaging test is indicated have included if the study was one that a cancer specialist would routinely perform for any given condition, or if the study has aided them in determining their patients' diagnoses or in the formulation of specific treatment plans (Miller, et al., 2015). Out of a sample of 113 cancer patients, at least $30 \%$ were referred with a minimum of one unhelpful study. Specifically, $74 \%$ of CT scans, $62 \%$ of bone scans and $50 \%$ of the referred PET scans were thought to be unhelpful (Miller, et al., 2015). Almost $29 \%$ of the total nonindicated imaging investigations were referred by G.Ps. (Miller, et al., 2015). Nevertheless, such study possesses the limitation that the clinical indications for each case were assessed only by the treating orthopaedic oncologist, which introduces an element of potential bias and the need for better internal validity.

\subsection{3 - Factors relating to the type of imaging modality being requested}

In another Slovenian study by Zontar, et al., (2015), it was established that approximately $88 \%$ of all 2098 imaging referrals that were analysed from 90 national, medical centres have belonged to conventional plain radiography. Moreover, approximately $10 \%$ of these referrals were for CT scans, whilst fluoroscopic examinations and interventional procedures have only contributed to about $1.5 \%$ and $0.5 \%$ of the total imaging referrals, respectively.

Whilst CT was only representing approximately $10 \%$ of all radiology procedures being done in Slovenia, this modality has still contributed to approximately two thirds of the cumulative, effective radiation doses and thus, it is considered as a major source of radiation exposure to the population (Zontar, et al., 2015). Interventional procedures closely follow CT, since they have contributed to approximately $10 \%$ of the overall, cumulative effective radiation doses population (Zontar, et al., 2015). The requests for plain x-ray imaging also deserve special attention towards which further efforts for increasing radiation dose optimisation should be directed, mostly owing to their rapidly increasing use. In fact, conventional radiography has contributed a total, cumulative effective dose of $19.3 \%$ (Zontar, et al., 2015). 


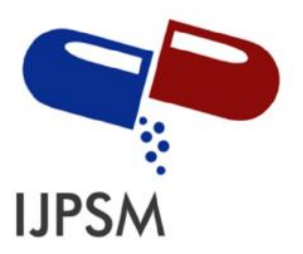

Georgiana Farrugia Bonnici, Int. Journal of Pharmaceutical Sciences and Medicine (IJPSM),

Vol.6 Issue. 4, April- 2021, pg. 92-115

ISSN: 2519-9889

Impact Factor: 3.426

This research has the advantage of investigating a larger sampling size with an increased generalizability of findings, because the authors have based their study across two university medical centres, ten general hospitals, thirteen specialised hospitals, thirty eight public health centres, as well as twenty seven other institutions; which have mostly included smaller private practices (Zontar, et al., 2015).

Comparably, in the study by Vilar-Palop, et al., (2018), the indications for the imaging referrals for mammography and CT scans were more likely to be appropriate than conventional plain radiographs or contrast-enhanced imaging procedures. These findings may be indicating the greater efforts that are made by the referring physicians to justify those imaging investigations that are either part of a screening programme, or else those investigations which are universally associated with higher radiation exposures. Contrastingly, Azman, et al., (2019) have reported that the mean effective radiation doses pertaining to ionizing imaging investigations may range anywhere between $122 \mathrm{mSv}$ to a maximum of $579 \mathrm{mSv}$ over a seven year period. This corresponds to an increased life-time cancer risk of one in 82 and one in 17, respectively. The increase in usage of higher-end imaging modalities, such as CT or PET scanning, is thought to be due to a combination of more tests being performed for common indications like headaches, trauma and seizures, as well as its expanded use for other emerging clinical indications, such as back pain or chest pain (Azman, et al., 2019). On the other hand, three other factors that may also increase the predisposition to the over-use of radiological services may include the poor integration of health-care services, the over-crowding of patients which may be also accompanied by reduced staffing levels, as well as litigious work environments that encourage the practices of defensive medicine (Mendelson and Montgomery, 2016; Azman, et al., 2019).

It has also been reported that patients frequently fail to provide their full medical histories either due to time constraints during limited medical consultations or due to a lack of understanding of the severity of their illnesses (Mendelson and Montgomery, 2016; Azman, et al., 2019). Furthermore, both emergency and family physicians may not have full accesses to all the radiographic records of their patients; potentially due to poor record-keeping or even if some of these patients have never been under their care before. These deficiencies could in turn promote the over-use of medical imaging services.

Morgan, et al., (2019) have also established that the over-use of medical imaging services is resulting in unnecessary costs to the health-care systems, as well as in avoidable exposures to ionizing radiation for patients. For this reason, a group of researchers have taken the initative to test a nationally-developed clinical referring proforma; that is the 2013 NPS MedicineWise LBP program. This electronic software has aimed to reduce the G.Ps referral rates for inappropriate imaging investigations in non-specific, acute low back pain in primary care clinics. It has provided the referrers with effective referral feedback patterns, fast decision support tools as well as simple patient information sources (Morgan, et al., 2019). This clinical referring proforma was indeed associated with a statistically significant $10.85 \%$ relative reduction in the volume of lumbo-sacral CT scans, equating to a cost reduction of approximately 11.6 million dollars (Morgan, et al., 2019). On the other hand, there was no observed associations between the regular uses of this particular clinical referral proforma to the volume of plain lumbo-sacral x-ray imaging referrals that were being requested by G.Ps (Morgan, et al., 2019). This research study bears the advantages that its representative findings are based over multiple primary health-care centres, as well as a long data collection process that was spanned over a total of five consecutive years. 


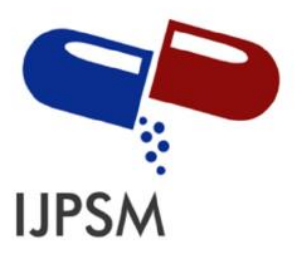

Georgiana Farrugia Bonnici, Int. Journal of Pharmaceutical Sciences and Medicine (IJPSM), Vol.6 Issue. 4, April- 2021, pg. 92-115

ISSN: 2519-9889

Impact Factor: 3.426

\section{1 - Conclusion to the literature review}

This systematic literature review has highlighted several important aspects that are already known with respect to the radiation dose justification and optimisation. Moreover, it has evaluated the current main issues relating to the physicians' awareness in radiation safety and imaging referral processes, as well as the appropriateness behind requesting ionizing imaging investigations. It has provided a summarized, systematic critique of several primary sources of literature with a direct assessment of their quality and consistency, in the form of any similarities and differences that were reported in various relevant research findings, whilst taking into consideration both the strengths and the weaknesses in their reported methodologies. This literature review has also served in deriving objectivity and accuracy in the conceptualization of the research questions through an in-depth assessment of the current available knowledge on this particular research topic. Certain gaps and conflicts in the literature were also identified.

\section{References}

[1]. Almen, A., Leitz, W., Richter, S. (2009). National survey on justification of CT-examinations in Sweden. SSM Report 2009:03 ISSN: 2000-0456. Stockholm, Sweden.

[2]. Ashurst, J.V., Cherney, A.R., Evans, E.M. (2014). Research priorities for the influence of gender on diagnostic imaging choices in the emergency department setting. Acad Emerg Med 2014;21:1431-7.

[3]. Austrian Society of Nuclear Medicine and Molecular Imaging. Support for Orientation in Radiology. Accessed via http://orientierungshilfe.vbdo.at on 20 Dec 2018.

[4]. Azman, R.R., Shah, M.Z., Hoong N.K. (2019). Radiation safety in emergency medicine: Balancing the benefits and risks. Korean J Radiol (2019):20(3)399-404.

[5]. Bedetti, G., Pizzi, C., Gavaruzzi, G., Lugaresi, F., Cicognani, A., Picano, E. (2008). Sub-optimal awareness of radiologic dose among patients undergoing cardiac stress scintigraphy. J Am Coll Radiol 2008;5:126-31.

[6]. Belgian Society for Nuclear Medicine. Recommendations for Medical Imaging. Accessed via www.health.belgium.be/richtlijnen-medische-beeldvorming on 20 Dec 2018.

[7]. Borgen, L., Erling, S., Ansgar, E. (2010). Clinicians' justification of imaging: do radiation issues play a role? Insights Imaging (2010) 1:193-200.

[8]. Britt, H., Miller, G., Valenti L. (2012). Evaluation of imaging ordering by general practitioners in Australia. Sydney University Press. Accessed from www.hdl.handle.net on January, 9, 2020.

[9]. Brownlee, S., Chalkidou, K., Doust, J, (2017). Evidence for overuse of medical services around the world. Lancet 2017;390:156-68.

[10].Campanella, F., Rossi, L., Giroletti, E.,Micheletti, P., Buzzi, F., Villani, S., (2017). Are physicians aware enough of patient radiation protection? Results from a survey among physicians of Pavia District- Italy. BMC Health Services Research (2017) 17:406.

[11].Cesur, G. (2009). Turkish pediatric surgeons knowledge on radiation exposure of patients during diagnostic imaging. Turkie Klinikerie J Med Sci.(2009).

[12].Czech society of nuclear medicine. National radiological standards. Accessed via https://is.cuni.cz/studium/predmety/index.php?do= predmet\&kod=B01254 on 20 Dec 2018.

[13].Dutch Radiological Society. Dutch Diagnostic Reference Levels phase 1 and phase 2. Accessed via www.referentieniveau.nl on 20 Dec 2018.

[14].European Commission (2001). Radiation protection 118: referral guidelines for imaging. Luxembourg: Office for Official Publications of the European Communities.

[15].European Commission (2008) European Commission guidance on estimating population doses from medical X-ray procedures (Radiation Protection No 154). Luxemburg: Office for Official Publications of the European Communities; 2008.

[16].European Commission (2015). Medical radiation exposure of the European population. Radiation Protection 180. Luxembourg: Publications Office of the European Union, 2015. ISBN: 978-92-79-45374-8. 


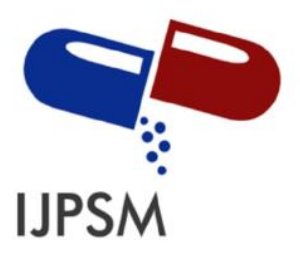

Georgiana Farrugia Bonnici, Int. Journal of Pharmaceutical Sciences and Medicine (IJPSM), Vol.6 Issue. 4, April- 2021, pg. 92-115

ISSN: 2519-9889

Impact Factor: 3.426

[17].European Society of Radiology (2011). White paper on radiation protection by the European Society of Radiology. Insights Imaging (2011) 2:357-362.

[18].European Society of Radiology (2015). Summary of the European Directive 2013/59/Euratom: essentials for health professionals in radiology. Insights Imaging (2015) 6:411-417.

[19].Faulkner, K., Zoetelief, J., Schultz, F.W., Guest, R. (2008). Safety and efficacy for new techniques and imaging using new equipment to support European legislation: 2008 Delft Conference Proceedings, Delft, Holland. Radiat Prot Dosimetry 2008;129:1-2.

[20].Fazel, R., Krumholz, H.M., Wang, Y., Ross, J.S., Chen, J., Ting, H.H., Shah, N.D., Nasir, K., Einstein, A.J., Nallamothu, B.K. (2009). Exposure to low-dose ionizing radiation from medical imaging procedures. N Engl J Med 361:849-857.

[21].Greenberg, J., Green, J.B., Yin, L. (2014).Over-testing: why more is not better. Am J Med 2014;127:362-3.

[22]. Grove, S.K., Cipher, J. D., (2019) Statistics for nursing research: A workbook for evidence-based practice. $2^{\text {nd }}$ edition. UK: Elsevier Publishers.

[23]. Hamada, N., Fujimichi, Y. (2014). Classification of radiation effects for dose limitation purposes: history, current situation and future prospects. $J$ Radiat Res 2014;55:629-40.

[24].Hill, K.D., Einstein, A., (2016). New approaches to reduce radiation exposure. Trends Cardiovasc Med. 2016 January ; 26(1): 55-65.

[25].Italian Association of Nuclear Medicine (AIMN). Recommendations on Nuclear Medicine Procedures. Accessed via http://www.aimn.it/pubblicazioni/LG/LG.php on 20 Dec 2018.

[26]. Khamtuikrua, C., Suksompong, S., (2020). Awareness about radiation hazards and knowledge about radiation protection among health-care personnel: A quaternary care academic center-based study. Sage Open Medicine. Volume 8, 1-8.

[27].Lauer, M.S. (2009) Elements of danger-the case of medical imaging. N Engl J Med 361:841-843.

[28].Lehnert, B.E., Bree, R.L. (2010). Analysis of appropriateness of outpatient CT and MRI referred from primary care clinics at an academic medical center: how critical is the need for improved decision support? J Am Coll Radiol 2010;7:192-7.

[29].Lim, Y.Z., Chou, L., Rau, T.M. (2019). People with low back pain want clear, consistent and personalized information on prognosis, treatment options, and self-management strategies: A systematic review. Journal of Physiotherapy (65)2019, 124-135.

[30].LoBiondo-Wood, G., Haber, J. (2017). Nursing Research: Methods and critical appraisal for evidence-based practice. $9^{\text {th }}$ edition. UK: Elsevier Publishers.

[31].Lumbreras, B., González-Alvarez' I., Gómez-Sáez’ M., Fermina Lorente’ M. (2018). Management of patients with incidental findings in imaging tests: a large prospective single-center study. Clin Imaging 2018;38(3):249-54.

[32]. Rehani, M. M. (2017) “Patient radiation exposure and dose tracking: a perspective, ” J. Med. Imag. 4(3), $031206,2017$.

[33].Malone, J., O’Connor, U., Faulkner, K. (2009). Ethical and justification issues in medical radiation protection. Radiat Prot Dosimetry Special Issue 2009; 135:Issue 2.

[34].Malone, J. (2008) Radiation protection, ethics, law and public awareness: in harmony or out of tune. European Congress of Radiology (ECR) Book of Abstracts. Eur Radiol Suppl 2008;18:128.

[35].Malone, J., Guleria, R., Craven, C. (2012). Justification of diagnostic medical exposures: some practical issues. Report of an International Atomic Energy Agency Consultation. The British Journal of Radiology 85 (2012), 523-538.

[36].Mendelson, R.M., Montgomery, B.D. (2016). Towards appropriate imaging: Tips for practice. The Royal Australian College of General Practitioners 2016. AFP Vol.45, No.6, June 2016.

[37].Miller, J.D., Avedian, R.S., Rajani. R. (2015). What is the use of imaging before referral to an orthopaedic oncologist? A prospective, multi-center investigation. Clinical orthopaedics and related research (2015): 473:868-874.

[38].Morgan, T., Wu, J., Ovchinikova, L., (2019). A national intervention to reduce imaging for low back pain by general practitioners: a retrospective economic program using medicare benefits schedule data. BMC Health Services Research, (2019)19:983.

[39].Moynihan, R., Doust, J., Henry, D. (2012). Preventing over-diagnoses: How to stop harming the healthy. BMJ 2012;344:e3502.

[40]. Oikarinen H, Merilainen S, Pakko“E, Karttunen A, Nieminen MT, Tervonen O. (2009). Unjustified CT examinations in young patients. Eur Radiol 2009;19:1161-5.

[41].Park, M., Seung Jung, E., (2016). Patient Dose Management: Focus on Practical Actions. J Korean Med Sci 2016; 31: S45-54.

[42].Pitman, A.G. (2017). Quality of referral: What information should be included in a request for diagnostic imaging when a patient is referred to a clinical radiologist? Journal of Medical Imaging and Radiation Oncology, 61(2017); $299-303$. 


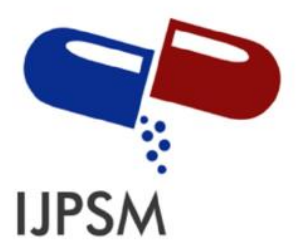

Georgiana Farrugia Bonnici, Int. Journal of Pharmaceutical Sciences and Medicine (IJPSM), Vol.6 Issue. 4, April- 2021, pg. 92-115

ISSN: 2519-9889

Impact Factor: 3.426

[43]. Radiological society of Finland. Radiation safety law. Accessed via http://www.stuk.fi/julkaisut_maaraykset/viranomaisohjeet/en_GB/stohjeet on 20 Dec 2018.

[44]. Rawle, M., Pighills, A. (2018) Prevalence of unjustified emergency department X-ray examination referrals performed in a regional Queensland hospital. J Med Radiat Sci 2018; 65: 184-91.

[45].Redondo-Sendino, A., Guallar-Castillón,. P, Banegas, J.R., (2016). Gender differences in the utilization of health-care services among the older adult population of Spain. BMC Public Health 2016;6:155.

[46].Remedios, D., Brkljacic, B., Ebdon-Jackson, S., Hierath, M., Sinitsyn, A., Vassilev, J. (2018). Collaboration, campaigns and champions for appropriate imaging: feedback from the Zagreb workshop. Insights into Imaging 2018; 9:211-214.

[47].Remedios, D., Hierath, M., Ashford, N, Cavanagh, C., Grenier, P.A., Lloyd, C.M., Simeonov, G., Simonnet, J.A, Vilgrain, V. (2014). European survey on imaging referral guidelines. Insights Imaging (2014) 5:15-23.

[48].Romanian Society of Nuclear Medicine. Guideline for using Radiology and Medical Imaging procedures. Accessed via www.ms.ro on 20 Dec 2018.

[49].Royal College of Radiologists (RCR) (2017). iRefer Imaging Referral Guidelines: Making the best use of clinical radiology, 8th edition. London: The Royal College of Radiologists, 2017. Accessed via http://www.rcr.ac.uk/content.aspx?PageID=995 on 28 Dec 2019.

[50].Sa Dos Reis, C., Bennett, C. Zhonghua, S. (2018). Education and training as a strategy to improve justification of medical imaging referrals in emergency departments. J Med Radiat Sci 65 (2018) 173-174.

[51].Sang-Geon, C., Jahae, K., Ho-Chun S. (2017). Radiation Safety in Nuclear Medicine Procedures (2017). Nucl Med Mol Imaging (2017) 51:11-16.

[52].Shannoun, F., Blettner, M., Schmidberger, H., Zeeb, H. (2008). Radiation protection in diagnostic radiology. Dtsch Arztebl Int 2008; 105(3): 41-6.

[53]. Slovak Society of nuclear medicine and radiation hygiene. Accessed via http://www.ssnm.sk on 20 Dec 2018.

[54]. Société Française de Radiologie. Guide du bon usage des examens d'imagerie médicale. Accessed via http://gbu.radiologie.fr. on 20 Dec 2018.

[55].Soye, J.A., Paterson, A. (2008). A survey of awareness of radiation dose among health professionals in Northern Ireland. Br J Radiol 81:725-729.

[56].Spanish society radiology. Guidelines of college of radiologists. Accessed via http://seram.es/modules.php?name=webstructure\&lang= ES\&idwebstructure=100 on 20 Dec 2018.

[57].Suman, A., Scaafhmsa, F.G., Van de Ven, P.M. (2018). Effectiveness of a multi-faceted implementation strategy compared to usual care on low back pain guideline adherence amongst general practitioners. BMC Health Services Research (2018).

[58].Swiss Society of Nuclear Medicine. PET guidelines of the Swiss Society of Nuclear Medicine. Accessed via http://www.nuklearmedizin.ch/index.php/fachpersonen_klv-richtlinien_menu- item/fachpersonen_klv-richtlinien_fdgpet-ct_on 20 Dec 2018.

[59].Tahvonen, P., Oikarinen, H., Pääkkö, E. (2013). Justification of CT examinations in young adults and children can be improved by education, guideline implementation and increased MRI capacity. Br J Radiol 2013;86.

[60]. The Danish Society of Radiology. Guidelines from the national institute for radiation protection. Accessed via www.drs.dk. On 20 Dec 2018.

[61].Vilar-Palop, J., Hernandez-Aguado, I., Pastor-Valero, M., Vilar, J., González-Alvarez, I., Lumbreras, B. (2018). Appropriate use of medical imaging in two Spanish public hospitals: a cross-sectional analysis. BMJ Open 2018;8:e019535.

[62].Vom, J., Williams, I. (2017). Justification of radiographic examinations: What are the key issues? J Med Radiat Sci 64 (2017) 212-219.

[63].Woo Kyoung, J., Jung Hwan, B., Seung Eun, J., Kyung Hyun, D., Hwan Seok, Y., Min-Jeong, K., Miyoung, C., Min, L., Sol Ji, C., Ae Jeong, J., Jin, A.C. (2016). Imaging Guidelines for Enhancing Justifications for Radiologic Studies. J Korean Med Sci 2016; 31: S38-44.

[64].Zigman Suschland, M.L., Witwer, E., Truit, A.R. (2019). Patient-centred outcomes related to imaging testing in US primary care. J Am Coll Radiol (2019) 16:2, 156-163.

[65].Zontar, D., Zdesar, U., Kuhelj, D., Pekarovic, D., Skrk D. (2015). Estimated collective effective dose to the population from radiological examinations in Slovenia. Radiol Oncol 2015; 49(1): 99-106. 


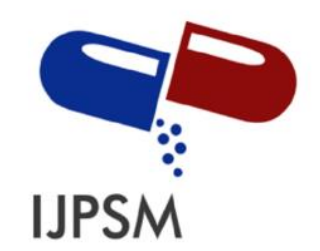

Georgiana Farrugia Bonnici, Int. Journal of Pharmaceutical Sciences and Medicine (IJPSM),

Vol.6 Issue. 4, April- 2021, pg. 92-115

ISSN: 2519-9889

Impact Factor: 3.426

\section{A Brief Author Biography}

Georgiana Farrugia Bonnici, BSc (Hons) Radiography, M.D., MSc Family Medicine - Dr. Georgiana Farrugia Bonnici is a former diagnostic radiographer and a junior medical doctor. She has completed a Masters of Science in Family Medicine. Her research field interests are cardiology, respiratory medicine and radiology. 